\title{
The Effect of Human Chorionic Gonadotropin Therapy on Semen Parameters and Pregnancy Rate after Varicocelectomy
}

\author{
Javanmard Babak $^{\mathrm{a}} \quad$ Fadavi Behruz $^{\mathrm{a}} \quad$ Yousefi Mohammadreza $^{\mathrm{a}} \quad$ Fallah-Karkan Morteza $^{\mathrm{b}}$ \\ aUrology Department, Shohada-e-Tajrish Hospital; ' Infertility and Reproductive Health Research Center, \\ Shahid Beheshti University of Medical Sciences, Tehran, Iran
}

\section{Key Words}

Human chorionic gonadotropin • Pregnancy • Varicocelectomy

\begin{abstract}
Introduction: To study the stimulating effect of human chorionic gonadotropin ( $\mathrm{hCG}$ ) on spermatogenesis in patients with varicocele and infertility undergoing varicocelectomy. Materials and Methods: In the study, 188 infertile patients with varicocele were included. Open inguinal varicocelectomy was performed. They were randomized into 2 groups and hCG (91 patients) was administered intramuscularly by dosage of 5,000 international units every week for 3 months. A semen analysis was obtained at 6 months, post-operatively and cases were followed for 2 years for pregnancy report. Results: Semen analysis of the patients shows a significant improvement in all parameters 6 months after varicocelectomy without any superiority between the 2 groups. During the follow-up, 56 couples $(61.5 \%)$ in hCG treated and 22 couples $(22.7 \%)$ in the group treated only by varicocelectomy achieved pregnancy. Patients treated with varicocelectomy plus hCG therapy had a significant superior pregnancy rate compared to the other group $(P=0.0001)$. Conclusion: Administration of hCG in this group of infertile patients might be helpful in order to enhance pregnancy rate. However some more conclusive studies are needed to be able to recommend such therapy for infertile men due to varicocele.
\end{abstract}

\section{KARGER}

Fax +4161306 1234

E-Mail karger@karger.com

www.karger.com
(C) 2017 S. Karger AG, Basel

Accessible online at: www.karger.com/cur

\section{Introduction}

Varicocele is dilation in the pampiniform plexus of veins in scrotal sac, secondary to the retrograde flow of blood to the testicle [1]. It affects $15 \%$ of adolescent population and it is considered to be the most common correctable pathology found in young men with infertility [2]. The common goal of all treatments is to eliminate the retrograde reflux of venous blood through the internal spermatic veins [1]. We are still unsure of the exact mechanisms by which varicocele impairs fertility and why interrupting the venous outflow at varicocelectomy results in improved fertility. Several theories have been developed on the pathogenesis, including scrotal hyperthermia, increased testicular blood flow, reflux of renal and adrenal metabolites, and endocrine dysfunction. Leydig cell dysfunction and subsequent pituitary hormone abnormality may be involved in the mechanism responsible for infertility in varicocele patients [3, 4]. For many years authors have reported that the presence of varicocele exerts a negative effect on spermatogenesis [5]. Given the wide application of intracytoplasmic sperm injection during the last few years, the modern research approaches should compare the benefits of varicocelectomy and intracytoplasmic sperm injection, taking under consideration both the efficacy and the cost-effectiveness of the methods [6]. It has demonstrated that sperm production in normal men can be reinitiated by supra physiologic dosages of human chorionic gonadotropin (hCG).

Morteza Fallah-Karkan

Infertility and Reproductive Health Research Center

Shahid Beheshti Medical Science

Tehran (Iran)

E-Mail mortezafallah.md@gmail.com 


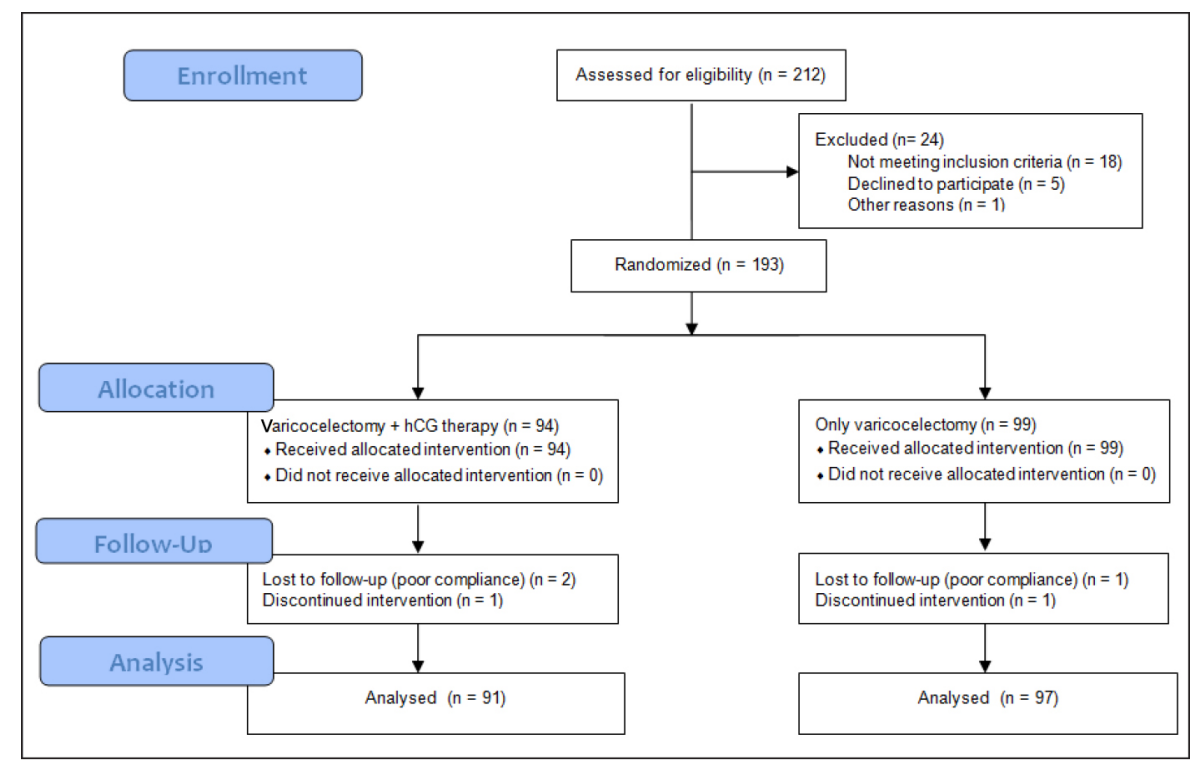

Fig. 1. Flowchart diagram.

The last studies extended findings by demonstrating that hCG can also stimulate spermatogenesis after a prolonged period of gonadotropin suppression [7]. In male hypogonadal patients with hypothalamic or pituitary gland dysfunction, gonadotropin-releasing hormone or gonadothrophin has been applied successfully for many years [6]. Based on inadequate studies, we decided to study the stimulating effect of hCG on spermatogenesis and pregnancy rate in patients with varicocele and abnormal semen analysis.

\section{Materials and Methods}

Between July 2012 and August 2014, varicocelectomy through an inguinal approach under $\times 3.5$ loupe magnification was performed for 188 patients, diagnosed with varicocele.

\section{Sample Size}

We calculated the sample size for this study according to Yamamoto et al. [7] study and this formula:

$$
\mathrm{N}=\frac{\mathrm{Z}^{2} \times(\mathrm{p}) \times(1-\mathrm{p})}{\mathrm{c}^{2}}
$$

\section{Subjects and Procedures}

Diagnosis was based on physical examination and was confirmed by ultrasonogram study. Infertile patients with varicocele and an abnormal semen analysis were included in the study. Infertility was defined as: failure to achieve a clinical pregnancy after 12 months or more of regular unprotected sexual intercourse.
Infertility due to any other reason (for example: history of cryptorchidism, endocrinopathy, testicular failure or ejaculatory dysfunction and patient that history of testicular sperm extraction) was considered as an exclusion criterion. Gynecological problems were ruled out for every patient's wives. Abnormal semen parameters were considering World Health Organization (WHO) (2010) classifications.

Using random block randomization patients were divided into 2 groups, the first one for which hCG was administered after the surgery consisted of 91 patients and there were 97 patients in the second group which only varicocelectomy was performed for them (fig. 1). One week after the surgery, hCG was administered intramuscularly by dosage of 5,000 international units (IU) every week for 3 consecutive months. A semen analysis was obtained at 6 months, postoperatively and cases were followed for 2 years for pregnancy report by touch in phone.

Semen was collected after a minimum of 3 days of abstinence. The spermograms of all the patients reported sperm counts, general motility and morphology before and after the treatment. The specimens were evaluated according to the standard procedures recommended by the WHO sperm analysis system, considering the WHO (2010) classifications [8].

\section{Ethics}

Ethical approval for the study was attained from the hospital's committee of the patient's ethical rights.

\section{Statistics}

We used SPSS 18 (statistical package for social sciences, Chicago, IL) to analyze data. In order to compare 2 groups, we used Chi-square test for categorical variable and independent $t$-test for continuous variables. Paired $t$-test was used for comparing 2 related mean in each group. P value less than 0.05 was considered statistically significant. 
Table 1. Demographic data of patients in 2 groups

\begin{tabular}{lrr}
\hline Variables & $\begin{array}{c}\text { Varicocelectomy }+ \text { hCG group } \\
(\mathrm{n}=91)\end{array}$ & $\begin{array}{c}\text { Varicocelectomy group } \\
(\mathrm{n}=97)\end{array}$ \\
\hline Age, year (mean \pm SD) & $29.91 \pm 2.67$ & $32.79 \pm 3.12$ \\
Marriage duration, year (mean \pm SD) & $4.89 \pm 1.10$ & $5.93 \pm 1.97$ \\
*History of underlying disease, $\mathrm{n}(\%)$ & $23(25.27 \%)$ & $28(28.86 \%)$ \\
Time of try for fertility (mean \pm SD) & $7.81 \pm 2.22$ & $6.41 \pm 1.93$ \\
$*$ **History of medicinal therapy, n (\%) & $78(85.71 \%)$ & $85(87.62 \%)$ \\
Grade of varicocele, n (\%) & & 0.59 \\
$\quad$ II & $33(36.26 \%)$ & $45(46.39 \%)$ \\
$\quad$ III & $58(63.73 \%)$ & $52(53.60 \%)$ \\
\hline
\end{tabular}

"Diabetes mellitus, hyperlipidemia, cancer, abdominal surgery, herniorrhaphy, etc.; "*vit E, L carnitine, vit C, pentoxifylline, Q 10 coenzyme, etc.

Table 2. Pre- and post-operative sperm parameters

\begin{tabular}{|c|c|c|c|c|c|c|}
\hline \multirow{2}{*}{ Variables } & \multicolumn{3}{|c|}{ Varicocelectomy + hCG group } & \multicolumn{3}{|c|}{ Varicocelectomy group } \\
\hline & Before varicocelectomy & After varicocelectomy & $\mathrm{p}$ & Before varicocelectomy & After varicocelectomy & $\mathrm{p}$ \\
\hline Sperm concentration, $10^{6} / \mathrm{ml}($ mean $\pm \mathrm{SD})$ & $10.8 \pm 4.1$ & $22.2 \pm 4.7$ & $<0.001$ & $11.1 \pm 3.9$ & $22.8 \pm 2.6$ & $<0.001$ \\
\hline Sperm motility, \% (mean \pm SD) & $35.8 \pm 4.3$ & $56.3 \pm 5.1$ & $<0.001$ & $31.6 \pm 3.6$ & $60.1 \pm 7.4$ & $<0.001$ \\
\hline Normal sperm morphology, $\%($ mean $\pm \mathrm{SD})$ & $28.8 \pm 2.5$ & $59.5 \pm 5.1$ & $<0.001$ & $29.5 \pm 6.1$ & $62.3 \pm 5.9$ & $<0.001$ \\
\hline
\end{tabular}

\section{Results}

Open inguinal varicocelectomy was performed for 188 patients, eligible to the inclusion criteria of the study. They were divided into 2 groups, with 91 (varicocelectomy + hCG) and 97 (varicocelectomy) patients.

\section{Demographic Data}

Two groups were matched in demographic data. The mean age of the patients was $31.5 \pm 4.2$ years $(29.91 \pm$ 2.67 in varicocelectomy + hCG group vs. $32.79 \pm 3.12$ in varicocelectomy group). The mean duration of marriage was $5.12 \pm 2.31$ years. Other demographic data is listed in table 1 .

\section{Surgical Data}

The mean duration of infertility was $2.1 \pm 0.8$ years. In the first group after the surgery hCG was administered, every week for 3 months. Comparing semen analysis of the patients shows a significant improvement in all semen parameters (concentration, morphology and motility) 6 months after varicocelectomy. The data could not indicate any superiority in improvement of semen pa- rameters between the 2 groups. Table 2 shows the results of semen analysis.

The mean follow-ups period for hCG group and only varicocelectomy group were $20 \pm 3.5$ and $19.8 \pm 4.1$ months, respectively $(\mathrm{p}=0.037)$. During the follow-up period $56(61.5 \%)$ couples in hCG treated group $(23$ couples in the first 6 month, 14 couples in the second 6 month, 9 couples in the third 6 month and 10 couples in the fourth 6 month ) and $22(22.7 \%)$ couples in the group (10 couples in the first 6 month, 7 couples in the second 6 month, 4 couples in the third 6 month and 1 couples in the fourth 6 month ) treated only by varicocelectomy achieved pregnancy. Although pregnancy rate increased in both group, patients treated with varicocelectomy plus hCG therapy had a significant superior pregnancy rate compared to the other group $(\mathrm{p}=0.0001)$.

\section{Side Effects}

There were 4 minor adverse effects $(4.39 \%)$ in hCG group ( 1 headache and 2 depressions and 1 restlessness). There were no major adverse effects like allergic reactions, deep vein thrombosis and multiple pregnancies. In varicocelectomy group there were 2 hydrocele $(2.06 \%)$ and 1 hematoma (1.03\%). 


\section{Discussion}

The precise hormonal milieu necessary for quantitatively normal spermatogenesis in men is unclear. The pituitary gonadotropin, luteinizing hormone (LH), and follicle-stimulating hormone (FSH), are clearly important regulators of sperm production. We evaluated in this study the effect of hCG therapy on semen parameters and pregnancy rate after varicocelectomy. There are many situations related to infertility in which the effect of hCG therapy is assessed for better spermatogenesis like our study.

Warne et al. [9] evaluated the effect of adding hCG treatment for male hypogonadotropic hypogonadism in different populations and to identify characteristics predictive of spermatogenesis. They did their study on 100 men with complete idiopathic or acquired hypogonadotropic hypogonadism and patients underwent pretreatment with hCG for 3-6 months, followed by combination therapy with hCG and r-hFSH (150 IU 3 times weekly) for up to 18 months. They showed that a total of 81 men remained azoospermic but achieved normal serum testosterone concentrations after hCG pretreatment. Of these, $68(84.0 \%)$ achieved spermatogenesis and 56 $(69.1 \%)$ achieved spermatozoa concentrations $\geq 1.5 \times$ $10^{6} / \mathrm{ml}$. Matsumoto et al. [10] administered testosterone enanthate for 4 normal men for a duration of 9 months. They found that despite significant serum testosterone increase after administration of exogenous testosterone, intratesticular testosterone (ITT) levels are severely reduced as a result of endogenous gonadotropin suppression. After 9 months' abnormal semen analysis or sever oligospermia was detectable in all cases. At this point they started hCG, simultaneously administered with testosterone for 6 months and sperm count increased significantly in all 4 patients. The authors concluded that sperm production can be reinitiated by hCG after prolonged gonadotropin and testicular suppression. Throughout the study, FSH was reduced to undetectable levels, indicating that normal levels of FSH are not absolute requirement for reinitiation of sperm production. The authors later in another study were able to show that although initiation of spermatogenesis only needs hCG but maintenance of quantitatively normal spermatogenesis requires FSH [11]. Shinjo et al. [12] were able to show that hormonal therapy in men with nonobstructive abnormal semen analysis can affect ITT levels and spermatogenesis. Twenty patients who failed sperm retrieval procedure using microsurgical testicular sperm extraction, enrolled in hCG-based hormonal therapy prior to a second testicu-

hCG Therapy on Semen Parameters lar sperm extraction. The patient's ITT levels were determined from last extraction. A significant increase in ITT levels after hormone therapy was determined. Andò et al. [13] studied 108 varicocele patients and a control group of 46 men. Plasma gonadotropin levels were determined. Testosterone, 17-OH progesterone, dihydrotestosterone and estradiol were also assayed. Mean plasma testosterone levels were significantly decreased in varicocele patients while the basal 17-OH progesterone/testosterone ratio was significantly increased. Based on the results they concluded that in varicocele patients Leydig cell function was impaired. hCG is known to have LH-like activity due to cross-reaction with $\beta$ subunit of $\mathrm{LH}[7,8]$. Mechanism of action of hCG is the same as LH. Structurally $\beta$ subunit of both this glycoprotein hormone exhibit $80 \%$ of homology. Hence both binds on the same receptor and therefore have the same mechanism of action. In short hCG mimics the activity of LH the only difference being longer half-life of hCG [14].

In male hypogonadotropic hypogonadism testosterone therapy is sufficient for maturation and maintenance of secondary sex characteristics. For stimulation of spermatogenesis administration of gonadotropins is necessary. If pulsatile gonadotropin-releasing hormone is not indicated or desired, hCG is used as the source of LH activity to stimulate testosterone secretion by Leydig cells. We decided to use hCG in order to enhance spermatogenesis in infertile patients after varicocelectomy and observe its effect on pregnancy rate. Our study revealed that semen parameters were improved after the surgery in all patients but they did not show significant difference between the 2 groups. However, patients treated by hCG achieved a significant higher pregnancy rate.

Yamamoto et al. [7] used LH-releasing hormone test for patients with varicocele in order to distinguish cases with Leydig cell dysfunction. Those who failed to show a normal LH peak in response to LH-releasing hormone were considered to the Leydig cell dysfunction. After varicocelectomy, for 135 patients with Leydig cell dysfunction, 5,000 IU of hCG was administered every week for 10 weeks. All patients were followed for 2 years to confirm pregnancy. Fifty-five percent of patients achieved pregnancy and they showed significant increase in sperm density, percentage of sperm motility, normal form of sperm and serum testosterone level. The study by Dubin et al. [15] involved 427 patients treated over a 12-year period and showed that adjuvant hCG yields better seminal parameters and a higher pregnancy rate in compare to varicocelectomy alone. They treated patients with sperm counts of less than $10 \times 10^{6} / \mathrm{ml}$ with injections of hCG, 
4,000 units intramuscularly twice weekly for 10 weeks. A $55 \%$ improvement in semen quality and a $45 \%$ pregnancy rate was observed. Their results were in line with our outcomes. Cockett et al. [16] used clomiphene citrate $25 \mathrm{mg} / \mathrm{d}$ for 25 days with a 5-day rest and reported a $53 \%$ pregnancy rate. Following adjuvant endocrine therapy, Netto et al. [17] recommend repeating the patient's endocrine studies at 2 months, and if an increase in FSH is noted without improvement in the semen analysis, they suggest that therapy be discontinued. According to American Association of Clinical Endocrinologists clinical guideline hCG alone can initiate sperm production and it should be initial therapy of choice for at least 6-12 months. Therapy with hCG is generally started at 1,000 to 2,000 IU intramuscularly 2-3 times a week. Both testosterone levels and sperm counts should be monitored monthly. If sperm concentration is not improving after 6 months of treatment, then FSH can be added in the dose of $75 \mathrm{IU}$ intramuscularly 3 times a week along with hCG [18]. Our pregnancy rate is comparable with the results of previous studies. One of the shortcomings of our study seems to be the lack of hormonal evaluation. This item could be the topic of further studies to comprehend the physiologic mechanism leading to improved pregnancy rate in patients treated with adjuvant hCG after varicocelectomy.

\section{Conclusion}

Our results demonstrated that administration of hCG therapy beside varicocelectomy can improve the fertility rate and better spermatogenesis with lower adverse effects in patients with varicocele and abnormal semen analysis. This can lead to improve the pregnancy rate. We proposed that treatment of male infertility in varicocele with hCG may prove cost effective and one can achieve pregnancy naturally without assisted reproductive techniques related complication. It is recommended to use this choice for similar patients; however, performing more research in large scale population and multi-centric studies are needed to provide more evidence of using this choice. Also, long-term follow-up for patients in this research is required.

\section{References}

1 Simforoosh N, Ziaee SAM, Behjati S, Beygi FMA, Arianpoor A, Abdi H: Laparoscopic management of varicocele using bipolar cautery versus open high ligation technique: a randomized, clinical trial. J Laparoendosc Adv Surg Tech A 2007;17:743-747.

2 Méndez-Gallart R, Bautista-Casasnovas A, Estévez-Martínez E, Rodríguez-Barca P: Bipolar electrothermal vessel sealing system and 5-mm 2 expandable trocar approach in pediatric laparoscopic varicocelectomy: a successful time-effective technical refinement. Sur Laparosc Endosc Percutan Tech 2011;21:e256-e259.

3 Etriby A, Girgis SM, Hefnawy H, Ibrahim AA: Testicular changes in subfertile males with varicocele. Fertil Steril 1967;18:666671 .

4 Ibrahim AA, Awad HA, El-Haggar S, Mitawi BA: Bilateral testicular biopsy in men with varicocele. Fertil Steril 1977;28:663-667.

5 Zorgniotti AW, Macleod J: Studies in temperature, human semen quality, and varicocele. Fertil Steril 1973;24:854-863.

6 Kamischke A, Nieschlag E: Analysis of medical treatment of male infertility. Hum Reprod 1999;14(suppl 1):1-23.

7 Yamamoto M, Hibi H, Katsuno S, Miyake $\mathrm{K}$ : Human chorionic gonadotropin adjuvant therapy for patients with Leydig cell dysfunction after varicocelectomy. Arch Androl 1995;35:49-55.
8 World Health Organization: WHO laboratory manual for the examination and processing of human semen. 2010.

9 Warne DW, Decosterd G, Okada H, Yano Y, Koide N, Howles CM: A combined analysis of data to identify predictive factors for spermatogenesis in men with hypogonadotropic hypogonadism treated with recombinant human follicle-stimulating hormone and human chorionic gonadotropin. Fertil Steril 2009; 92:594-604.

10 Matsumoto AM, Bremner WJ: Stimulation of sperm production by human chorionic gonadotropin after prolonged gonadotropin suppression in normal men. $\mathbf{J}$ Androl1985;6:137-143.

11 Matsumoto AM, Karpas AE, Bremner WJ: Chronic human chorionic gonadotropin admininstration in normal men: evidence that follicle-stimulating hormone is necessary for the maintenance of quatitatively normal spermatogenesis in man. J Clin Endocrinol Metab 1986;62:1184-1192.

12 Shinjo E, Shiraishi K, Matsuyama H: The effect of human chorionic gonadotropinbased hormonal therapy on intratesticular testosterone levels and spermatogonial DNA synthesis in men with non-obstructive azoospermia. Andrology 2013;1:929-935.
13 Ando S, Giacchetto C, Colpi G, Beraldi E, Panno M, Lombardi A: Physiopathologic aspects of Leydig cell function in varicocele patients. J Androl 1984;5:163-170.

14 Padvi NV, Singh PP, Nadkarni KM, Singh PM: Interventional study to find out effect of human chorionic gonadotropin and antioxidants on idiopathic male infertility. Int J Reprod Contracept Obstet Gynecol 2017;6: 496-499.

15 Dubin L, Amelar R: The varicocele and infertility. Philadelphia, Saunders, 1977.

16 Cockett AT, Takihara H, Cosentino MJ: The varicocele. Fertil Steril 1984;41:5-11.

17 Rodriguez-Netto N: Varicocele: fact or fiction? in Paulson JD, Negro-Vilar A, Lucena E, Martini L (eds): Andrology: Male Fertility and Sterility. Academic Orlando, FL, 1986, pp233-245.

18 Camacho PM, Petak SM, Binkley N, Clarke BL, Harris ST, Hurley DL, Kleerekoper M, Lewiecki EM, Miller PD, Narula HS, Pessah-Pollack R, Tangpricha V, Wimalawansa SJ, Watts NB: American Association of Clinical Endocrinologists and American College of Endocrinology Clinical Practice Guidelines for the diagnosis and treatment of postmenopausal osteoporosis-2016. Endocr Pract 2016;22(suppl 4):1-42. 